\title{
DOMINANT MUTATIONS AT Cer-yY CHANGE BARLEY SPIKE WAX INTO LEAF BLADE WAX
}

\author{
by \\ UDDA LUNDQVIST ${ }^{1}$ and PENNY VON WETTSTEIN-KNOWLES ${ }^{2,3}$
}

\author{
ISvalöf AB, S-268 00 Svalöv, Sweden \\ 2Institute of Genetics, University of Copenhagen, \\ Øster Farimagsgade 2 A, DK-1353 Copenhagen K \\ 3 Department of Physiology, Carlsberg Laboratory, \\ Gamle Carlsberg Vej 10, DK-2500 Copenhagen Valby
}

Keywords: $\beta$-diketones, primary alcohols, epicuticular, early maturation, elongase, lipid, biosynthesis

Seventeen mutations resulting in an apparent loss of the epicuticular wax on barley spikes have been shown by complementation, test cross and $F_{2}$ analyses to be dominantly inherited alterations of the Cer-yy gene. The chemical composition determined by the four alleles $966,968,975$ and 984 differs from that determined by the wild type in that none of the $\beta$-ketoacyl derived lipids ( $\beta$-diketones, hydroxy- $\beta$-diketones and esters containing alkan-2-ols) are synthesized while the composition of the other wax lipids (alkanes, primary alcohols, aldehydes, esters containing alkan-1-ols and free acids) is markedly altered toward that characteristic of leaf blade waxes. We suggest that the Cer-yy gene determines a regulatory component which upon mutation activates the gene(s) in the spike for the leaf blade acyl elongase system and at the same time represses the spike acyl and $\beta$-ketoacyl elongase systems.

\section{INTRODUCTION}

Most induced visible mutations in barley are recessive (13). This is also the case for the eceriferum (cer) mutants which occur in at least 70 loci $(7,8,9)$. In the course of assigning 1355 induced mutants to these gene loci controlling the synthesis and excretion of the epicuticular waxes, 18 dominant mutants were encountered (8). Seventeen of these are alleles of a single gene Cer-yy. Their genetic analyses and biochemical

Abbreviations: fas = fatty acid synthetase; GLC = gas liquid chromatography; $\mathrm{TLC}=$ thin layer chromatography. 
characteristics are presented in this paper. The other dominant mutation is an allele of the gene $c e r-n$ at which 50 recessive alleles have been previously identified (8). This locus will be the subject of a subsequent paper.

\section{MATERIALS AND METHODS}

\subsection{Isolation of mutants and their genetic characterization}

The $\mathrm{M}_{1}\left(\mathrm{X}_{1}\right)$ barley plants (Hordeum vulgare L.) cv's. Bonus, Mari and Foma were grown at the Swedish Seed Association, Svalöv in plots surrounded by other crops to prevent outcrossing. The eceriferum mutants were isolated in $\mathrm{M}_{2}\left(\mathrm{X}_{2}\right)$ field material grown either at Svalöv or at the Agricultural Research Department of the Danish Atomic Energy Commission's Research Establishment, Risø. Identification of the mutants and phenotypic classification of progeny in genetic tests were by ocular inspection. Observations on pleiotropic effects associated with the cer phenotype were made simultaneously with the latter. That is, the plants were not inspected specifically for time of maturation. Reported results are the sum of observations made every year since the initial isolation of the cer mutant. To determine whether the new cer mutants were allelic with previously defined cer loci the following mutants used in diallelic crosses: cer$a^{1},-a^{913},-b^{147},-b^{1267},-c^{144},-d^{5},-d^{40},-e^{8},-e^{18}$, $-f^{9},-f^{763},-g^{10},-h^{13},-h^{233},-i^{25},-i^{51},-k^{39},-l^{14}$, $-m^{15},-n^{20},-n^{963},-o^{28},-q^{598},-r^{19},-r^{773},-s^{31}$, $-t^{22},-t^{46},-u^{776},-v^{49},-v^{752},-w^{48},-w^{280},-x^{60}$, $-y^{72},-z b^{38},-z b^{105},-z c^{65},-z c^{221},-z i^{68},-z i^{979}$, $-z n^{244},-z n^{362},-z 0^{229},-z 0^{352},-z r^{260},-z r^{528}$, $-z s^{467}, \quad-z s^{474}, \quad-z t^{389}, \quad-z t^{479}, \quad-z u^{122}, \quad-z x^{100}$, $-y c^{135},-y d^{139},-y h^{116},-y h^{654},-y r^{439},-y t^{758}$ and $-y t^{938}(8)$. The $F_{1}$ 's from all these crosses had a cer phenotype suggesting that the set of mutants being studied was dominant. This was confirmed by studying the $F_{2}$ generations. In scoring $F_{2}$ plants when the two cer mutations could be distinguished by their effect on the leaf sheath and internode wax, only the phenotype of the spike waxes was noted. Crosses of the dominant mutants with each other and their mother variety were also carried out.

\subsection{Observations on and wax collection from Phytotron grown plants}

For the chemical studies of spike waxes, seeds of Bonus as well as of the mutants 966, 968, 975 and 984 (Table I) were planted and grown to heading (approximately 56 days later) under optimum conditions for vegetative growth $(3,4)$ in the Phytotron at the Swedish University of Agricultural Science, Stockholm (15) between 1977 and 1980. Bonus barley for the leaf blade wax analysis was treated identically until just before the flag leaves started to emerge. One group of plants was then placed at $15^{\circ} \mathrm{C}$ with 20 hours of light and 4 hours of dark. A parallel group of plants was shifted to $25^{\circ} \mathrm{C}$ with the same photoperiod just described. The results are from the former set of plants, but no significant difference between the two temperature treatments was discovered.

Subsequent to collection of waxes from the spikes (section 2.3), the lengths from the uppermost node to the tip of the longest awn and to the tip of the highest seed's lemma were measured with a millimeter scale while the stem diameter 1 to $1.5 \mathrm{~cm}$ below the same node was determined with the aid of a caliper ruler. Values given are averages of 20 measurements.

\subsection{Chemical analyses}

Wax was collected from heading spikes (22) or the two uppermost leaf blades as described earlier $(14,16)$. The resulting chloroform solutions were dried using nitrogen. A Cahn model 4600 electrobalance (Cahn/Ventron Corp., Paramount, California) was used to weigh out 5.000 to $10.000 \mathrm{mg}$ of each wax sample from which dilution series were prepared. The optical density of a $1 \%$ solution of each wax sample in $0.5 \mathrm{~cm}$ hexane at $273 \mathrm{~nm}$ was determined with the aid of a Zeiss PMQ 3 spectrophotometer (Oberkochen, West Germany).

The lipid classes were separated using preparative thin layer chromatography (TLC) on silica gel $\mathrm{H}$ (Merck) plates that were developed first in hexane and second in benzene or amylene stabilized chloroform (Merck). Location of the lipids has been described (16). Hydrocarbons, esters, aldehydes and primary alcohols were eluted (16) using chloroform while the free acids 
Table I

Data on $\operatorname{Cer}-y y(-++++)$ barley mutantsa.

\begin{tabular}{|c|c|c|c|c|c|c|}
\hline Mutant & $\begin{array}{l}\text { Mother } \\
\text { variety }\end{array}$ & $\begin{array}{l}\text { Year of } \\
\text { isolation }\end{array}$ & Mutagen & Dose & $\begin{array}{l}\text { Conditions of } \\
\text { treatmentc }\end{array}$ & Special remarksd \\
\hline$-y y 437$ & Foma & 1967 & $\begin{array}{l}\text { ethylmethane- } \\
\text { sulfonate }\end{array}$ & $0.5 \% \times 5 \mathrm{~h}$ & resting & very early maturity \\
\hline 649 & Mari & 1967 & $\gamma$-rays & $7,500 \mathrm{rad}$ & $\begin{array}{l}\text { chronic } \\
\text { recurrent }\end{array}$ & early maturity \\
\hline 650 & Mari & 1967 & $\gamma$-rays & $7,500 \mathrm{rad}$ & $\begin{array}{l}\text { chronic } \\
\text { recurrent }\end{array}$ & early maturity \\
\hline 849 & Bonus & 1970 & ethylene-oxide & $0.14 \% \times 2 \mathrm{~h}$ & resting & early maturity \\
\hline 898 & Bonus & 1970 & $\begin{array}{l}\text { iso-propyl- } \\
\text { methane- } \\
\text { sulfonate }\end{array}$ & $0.6 \% \times 5 \mathrm{~h}$ & resting & early maturity (?) \\
\hline 919 & Mari & 1972 & $\gamma$-rays & $7,500 \mathrm{rad}$ & $\begin{array}{l}\text { chronic } \\
\text { recurrent }\end{array}$ & $\begin{array}{l}\text { very early maturity; simulta- } \\
\text { neous occurrence of mutations } \\
\text { for anthocyaninless (ant } 41 \text { ) } \\
\text { and resistance to powdery } \\
\text { mildew (SR 33), both not linked }\end{array}$ \\
\hline 920 & Bonus & 1970 & neutrons $b$ & $300 \mathrm{rad}$ & resting & early maturity, anthocyaninless \\
\hline 923 & Bonus & 1970 & neutrons $\mathbf{b}$ & $300 \mathrm{rad}$ & resting & anthocyaninless \\
\hline 929 & Bonus & 1970 & neutrons $b$ & $200 \mathrm{rad}$ & resting & $\begin{array}{l}\text { early maturity, simultaneous } \\
\text { occurrence of mutation for } \\
\text { anthocyaninless, not linked }\end{array}$ \\
\hline 935 & Bonus & 1970 & neutrons ${ }^{b}$ & $200 \mathrm{rad}$ & resting & early maturity, anthocyaninless \\
\hline 941 & Bonus & 1970 & $\begin{array}{l}\text { iso-propyl- } \\
\text { methane- } \\
\text { sulfonate }\end{array}$ & $0.6 \% \times 5 \mathrm{~h}$ & resting & early maturity, anthocyaninless \\
\hline 966 & Bonus & 1971 & neutrons $b$ & $200 \mathrm{rad}$ & resting & $\begin{array}{l}\text { early maturity, simultaneous } \\
\text { occurrence of mutation for } \\
\text { anthocyaninless, not linked }\end{array}$ \\
\hline 968 & Bonus & 1971 & neutrons ${ }^{b}$ & $200 \mathrm{rad}$ & resting & early maturity \\
\hline 975 & Bonus & 1973 & $\mathrm{X}$-rays & $10,000 \mathrm{rad}$ & resting & $\begin{array}{l}\text { early maturity (?); simultaneous } \\
\text { occurrence of mutations for } \\
\text { anthocyaninless and resistance } \\
\text { to powdery mildew (SR 50), } \\
\text { both not linked }\end{array}$ \\
\hline 982 & Bonus & 1971 & neutronsb & $300 \mathrm{rad}$ & resting & early maturity, anthocyaninless \\
\hline 983 & Bonus & 1971 & neutrons $b$ & $200 \mathrm{rad}$ & resting & early maturity \\
\hline 984 & Bonus & 1971 & neutrons ${ }^{b}$ & $200 \mathrm{rad}$ & resting & early maturity, anthocyaninless \\
\hline
\end{tabular}

a The amount of wax on each organ of the wild type is given as ++ , a reduced amount as + and an apparent lack of wax as a-(7). From left to right the phenotypic formula describes spikes, uppermost leaf sheaths plus internodes, leaf blades.

b Neutrons in reactor center (see 1).

c Refers to conditions of treated material:

resting $=$ resting seeds with a water content of $11 \%$.

chronic recurrent $=$ growing plants irradiated chronically from a ${ }^{137} \mathrm{Cs}$ source during the whole vegetation period two or three years in succession.

d Early maturity = heading several days before Bonus: ? = observed to be early in only one year since isolation.

Very early maturity = heading at least one week before Bonus, as does Mari.

SR = Svalöv's resistant mutant stock number to powdery mildew. 
were recovered using acetic acid acidified chloroform: methanol $(1: 1, \mathrm{v} / \mathrm{v})$. The isolated lipid classes and/or their derivatives (see 22) were analyzed via gas liquid chromatography (GLC) using the Hewlett-Packard instrumentation, the $3 \%$ SP-2100 and 1\% Dexsil-300 columns and the conditions detailed previously (22).

\section{RESULTS}

\subsection{Phenoty pic observations}

Table I lists the pertinent details concerning the origin and characterization of 17 dominant mutants at locus Cer-yy which were isolated from $\mathrm{M}_{2}$ populations over a seven year period. All 17 mutants are classified as -++++ (see footnote a, Table I). The mutants $649,650,919$ and 975 were isolated from sister $\mathrm{M}_{2}$ spikes to spikes which segregated in green house tests for resistance to powdery mildew. Neither 649 nor 650 proved to be resistant upon further investigation. The dominant resistance to powdery mildew induced in the same plant with the eceriferum phenotype of 919 and 975 was also present among cer plants, but could be segregated away from the cer phenotype. The two characters have been shown to be due to mutation in two different loci.

Association of specific groups of pleiotropic effects with alleles at various cer loci has been noted previously and discussed (9). In 10 of the 17 dominant mutants, the simultaneous induction of the absence of anthocyanin (ant) with that of the eceriferum character has occurred (Table I). In four cases $(919,929,966$ and 975$)$, the ant and cer phenotypes have been shown to be due to mutations at non-linked loci, by taking advantage of an observed segregation for the presence vs absence of anthocyanin in the eceriferum stock. To illustrate, the cross $\mathrm{Cer}$ yy 966 ant (anthocyaninless line) $\times$ wild type (Bonus) gave an $F_{2}$ segregation of $54 \mathrm{cer}: 14$ wild type : 12 cer ant : 0 ant which is not significantly different from the 9:3:3:1 ratio expected for two independent loci $\left(\chi^{2}=7.47\right)$. Cer-yy ${ }^{966}$ (anthocyanin containing line) $\times$ wild type gave 66 cer : 18 wild type while Cer-yy $y^{966}$ ant $\times$ Cer-yy ${ }^{966}$ gave $53 \mathrm{cer}: 16 \mathrm{cer}$ ant; both of which are good fits for 3:1 ratios $\left(\chi^{2}=0.57\right.$ and 0.12 , respectively). Segregation of anthocyanin containing lines in the $920,923,935,941,982$ and 984 cer stocks has not been observed, and no attempt has been made thus far to separate the anthocyaninless character from that of the eceriferum one. Experiments are in progress to answer this question, as well as to determine how many different ant loci are involved.

The other intriguing observation concerning the origin of the 17 mutants is the effect on the time of maturity that occurred simultaneously with 13 and perhaps 15 of the eceriferum mutations (Table I). Although we have not tried to determine whether the effect on maturity is a pleiotropic one of the cer mutation or is due to simultaneous induction of mutations at one or more additional loci, we believe the latter is more likely. We base this working hypothesis on the observation that in two cases no effect was found, while in two instances the time of maturity was later and in the remaining earlier than that of the mother variety. Given that our hypothesis is correct, it would be interesting to know how many different loci affecting maturity are involved in the 13 (15?) cases.

The four dominant mutants $966,968,975$ and 984 have been further investigated in the Phytotron. As in the field, plants with these mutations have shiny spikes and wax coats indistinguishable from wild type on the leaf sheaths, internodes and leaf blades. Eight weeks after sowing the mutant plants are markedly shorter than wild type plants. For example, in one experiment the lengths of the spikes including the awns were 18 to $20 \mathrm{~cm}$ vs 22 or more $\mathrm{cm}$ for those of Bonus. At that time each mutant plant had 5 to 6 tillers with the spikes totally emerged from the flag leaf sheaths vs 2 to 3 tillers for the wild type. Thus, in the Phytotron 975 , as well as 966,968 and 984 , would be definitely classified as an early maturer. In this connection the observation (GUSTAFsSON and LUNDQVIST, unpubl.) that 975 does not head at all when grown with a photoperiod of 8 hours light, 16 hours dark is of interest (5). Such behavior is characteristic of eight of the nine mat loci and the wild type Bonus, while the ninth mat- $a$ (gene giving early maturity in Mari) heads under these conditions $(4,6$, Gustafsson and LUNDQVIST, unpubl.). While the uppermost internode of the heading spikes extended 2 to 4 $\mathrm{cm}$ above the flag leaf sheath of Bonus, 5 to 12 $\mathrm{cm}$ were exposed on the four dominant mutants. 
The diameter of the stems of the latter, however, was less. That is, already 1 to $1.5 \mathrm{~cm}$ below the uppermost node, the internode diameter of the four studied mutants was 1.1 to $1.3 \mathrm{~mm}$ vs a minimum of $1.4 \mathrm{~mm}$ for those of the wild type. The 984 mutant stock investigated differed from the other three mutant stocks in lacking visible anthocyanin pigmentation.

\subsection{Genetic analyses}

All Fis arising from crosses between one of the 17 investigated mutants and the wild types Bonus or Mari had the same eceriferum pheno-

\section{Table II}

F2 segregations from Cer-yy $\times$ Bonus or Mari crosses.

\begin{tabular}{lccc}
\hline & \multicolumn{3}{c}{ Number of plants observed } \\
Cer-yy & Cer & Wild type & $\begin{array}{c}\text { x for } \\
3: 1\end{array}$ \\
\hline 437 & 2316 & 726 & 2.08 \\
\hline 649 & 710 & 256 & 1.16 \\
\hline 650 & 1933 & 728 & 7.89 \\
\hline 849 & 152 & 60 & 1.23 \\
\hline 898 & 99 & 41 & 1.37 \\
\hline 919 & 296 & 81 & 2.49 \\
\hline 920 & 154 & 40 & 1.98 \\
\hline 923 & 207 & 60 & 0.91 \\
\hline 929 & 263 & 87 & $<0.01$ \\
\hline 935 & 212 & 46 & 7.07 \\
\hline 941 & 96 & 30 & 0.09 \\
\hline 966 & 257 & 79 & 0.40 \\
\hline 968 & 271 & 93 & 0.06 \\
\hline 975 & 214 & 61 & 1.16 \\
\hline 982 & 292 & 108 & 0.85 \\
\hline 983 & 294 & 90 & 0.50 \\
\hline 984 & 145 & 51 & 0.11 \\
\hline
\end{tabular}

type $(-++++)$ as did the mutant parent, suggesting dominance of the apparent lack of spike wax over its presence. For 15 of the mutants (Table II), the $F_{2}$ progenies segregated $3 \mathrm{cer}: 1$ wild type which is the expected result if the mutant is completely dominant. Deviations from the expected 3:1 ratio as large as those observed for the crosses of the cer mutants 650 and 935 to wild type are expected only 0.5 to $1 \%$ of the time due to chance alone. We can offer no explanation as to why these two $F_{2}$ segregations differ so greatly from the expected.

All possible complementation tests among the 17 mutants (except $849 \times 929$ and $650 \times 984$ which have not yet been made) were negative, that is the plants had completely waxless appearing spikes. $F_{2}$ data is available for 125 out of the 136 possible combinations among these mutants. Should two dominant mutants of the same phenotype represent different loci, $F_{2}$ segregations of 15 mutant : 1 wild type would be expected. That this is not the case here is shown in Figure 1 which gives the number of plants scored in each $F_{2}$ progeny, all of which had cer spikes. In three of the missing combinations, one of the mutant parent lines was observed to segregate wild type individuals and the original cross has to be repeated. Data is not yet available for the other eight missing combinations. Despite the fact that the data are not quite complete and some of the $F_{2}$ progeny sizes are rather small, we feel confident that the results presented demonstrate that the 17 investigated mutants are dominant alleles at a single locus.

Genetic crosses have also been carried out to ascertain whether these dominant mutants belong to one of the other cer loci affecting wax on the spikes. Since the representative alleles at all these other loci are recessive to the wild type, the expected $F_{2}$ segregations arising from their being crossed with the dominant eceriferum mutants is $13 \mathrm{cer}: 3$ wild type. Table III presents the $\mathrm{F}_{2}$ segregations found after crossing the dominant mutants 898,941 and 982 with 25 different cer loci. Data for these three dominant mutants is presented since with one exception it is complete. Of the 350 possible combinations among the other 14 dominant cer mutants and the 25 specified cer loci, 309 of them have given $\mathrm{F}_{2}$ data similar to that presented in Table III. In every instance wild type plants were found in the $F_{2}$. 
Cer - yy

$\begin{array}{lllllllllllllllll}649 & 650 & 849 & 898 & 919 & 920 & 923 & 929 & 935 & 941 & 966 & 968 & 975 & 982 & 983 & 984\end{array}$

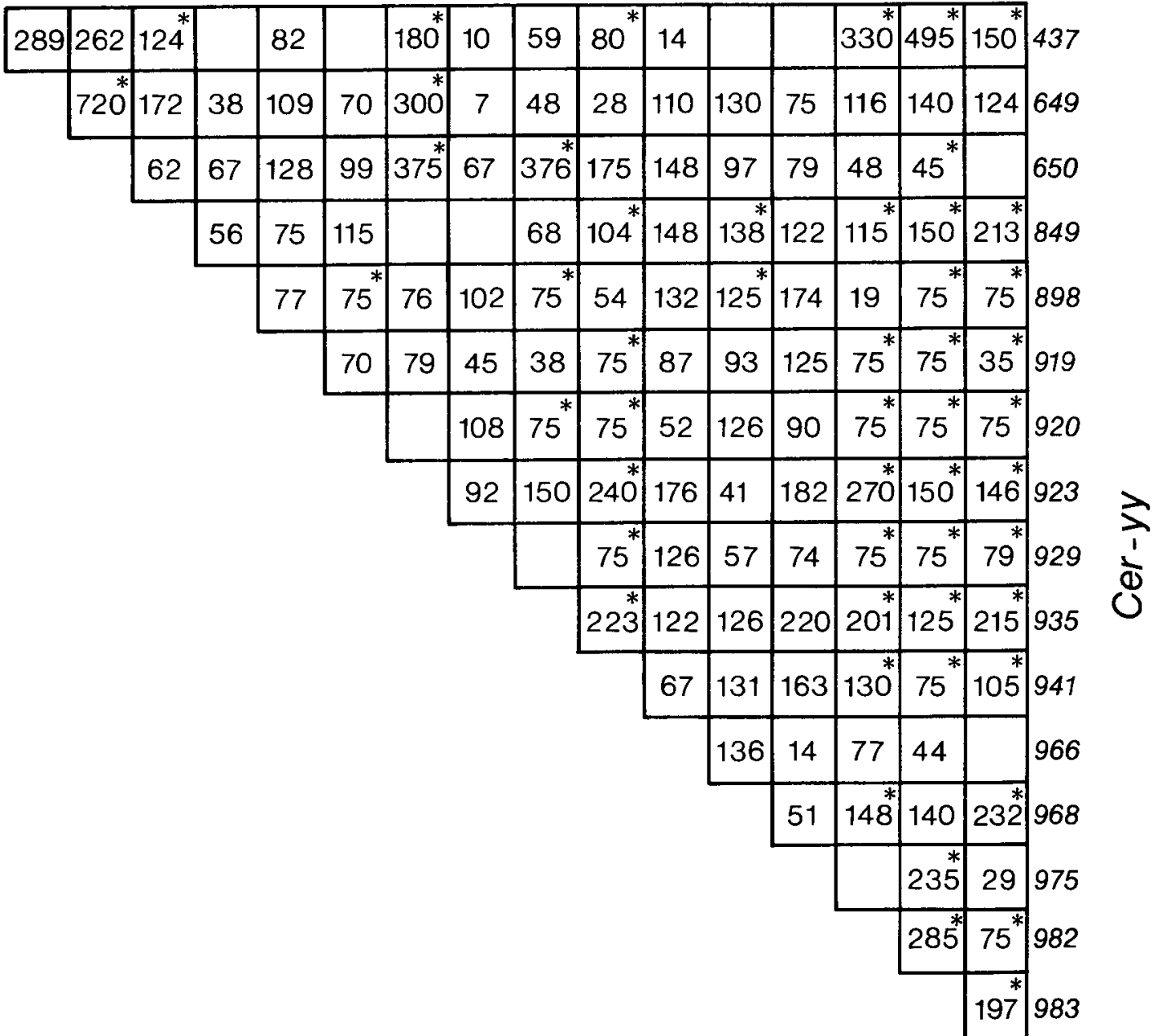

Figure 1. Number of $F_{2}$ plants scored from Cer-yy $\times$ Cer-yy crosses.

All $\mathrm{F}_{2}$ plants had a cer phenotype. ${ }^{*}=$ not all plants counted individually, but estimated in part from number of rows.

Since $F_{2}$ results for at least seven of the dominant mutants crossed with any one of the 25 forementioned tested loci are known, we conclude that the dominant cer locus being investigated is not allelic with any of them. Genetic tests have not yet been carried out with the other three identified - - ++ loci, namely $c e r-z,-z l$ and $-y l$, since the reduced viability of mutants in these loci makes it very difficult to carry out such analyses and their total phenotype is so markedly different from that of the dominant mutants.

Thirteen additional cer loci are known to affect the wax coating on the spikes $(++++)$ $F_{2}$ results are available for crosses between ten of them, namely cer $-f,-g,-m,-n,-r,-s,-y,-z i,-z u$ and $-z x$, and the dominant mutant 920 . The following segregations of cer: wild type were observed, respectively: $63: 11,60: 16,30: 12$, $172: 38,139: 30,58: 6,63: 8,127: 24,114: 17$, 
Table III

F 2 segregations from crosses of three $C e r-y y$ alleles with recessive alleles at $25 \mathrm{cer}$ locia.

\begin{tabular}{|c|c|c|c|c|c|c|}
\hline \multirow[b]{2}{*}{ Phenotype of $F_{2}$ : } & \multicolumn{2}{|c|}{898} & \multicolumn{2}{|c|}{ Cer $-y y$} & \multicolumn{2}{|c|}{982} \\
\hline & cer & WT & cer & WT & cer & WT \\
\hline$\times$ I. cer $-d$ & 45 & 6 & 181 & 45 & 96 & 20 \\
\hline$e$ & 59 & 11 & 388 & 119 & 95 & 28 \\
\hline$h$ & 66 & 12 & 195 & 72 & 82 & 24 \\
\hline$i$ & 55 & 7 & 90 & 25 & 70 & 16 \\
\hline$o$ & 23 & 9 & 53 & 24 & 52 & 12 \\
\hline$t$ & 87 & 17 & 340 & 79 & 220 & 41 \\
\hline$v$ & 123 & 21 & 291 & 106 & 168 & 32 \\
\hline$w$ & 27 & 10 & 254 & 68 & 120 & 24 \\
\hline$z b$ & 78 & 28 & 60 & 11 & 90 & 19 \\
\hline$z c$ & 158 & 29 & 99 & 23 & 90 & 17 \\
\hline$z n$ & 117 & 20 & 166 & 49 & 70 & 12 \\
\hline$z o$ & 62 & 16 & 236 & 87 & 107 & 26 \\
\hline$y c$ & 39 & 9 & 41 & 12 & 55 & 14 \\
\hline$y d$ & 45 & 7 & 48 & 15 & 51 & 7 \\
\hline$y h$ & 32 & 5 & 120 & 48 & 78 & 12 \\
\hline$y t$ & 113 & 27 & 73 & 11 & 118 & 18 \\
\hline II. cer-k & 49 & 27 & 54 & 10 & 25 & 4 \\
\hline$l$ & 30 & 6 & 56 & 13 & 49 & 19 \\
\hline$z r$ & 40 & 9 & 211 & 50 & 138 & 28 \\
\hline$z s$ & 132 & 28 & 152 & 29 & 123 & 20 \\
\hline$z t$ & 46 & 9 & 231 & 68 & 129 & 25 \\
\hline III. $c e r-a$ & 46 & 5 & 57 & 19 & 39 & 14 \\
\hline$b$ & 91 & 19 & 53 & 17 & & \\
\hline$x$ & 118 & 20 & 64 & 16 & 63 & 12 \\
\hline$c, q, u^{\mathrm{b}}$ & 71 & 17 & 144 & 44 & 195 & 50 \\
\hline
\end{tabular}

a The 25 loci are divided into three groups on the basis of their phenotypic formula. $\mathrm{I}=-++++$; II $=$ +++++ ; III $=--++$.

b Data combined since they represent a single locus. Phenotypic formula for cer- $u=++++$.

and 64:10. Similar $F_{2}$ segregations were obtained for 96 of the 160 possible combinations among the other 16 dominant mutants and the ten specified loci. These include a minimum of three dominant mutants crossed with each of the 10 loci under discussion. For the recently identified (8) cer-yr locus $(++++)$, the only $\mathrm{F}_{2}$ data thus far obtained is from crossing with the dominant mutant 929 . A ratio of $53 \mathrm{cer}: 13$ wild type occurred. We thus conclude that the dominant mutants being investigated are not allelic with these $11 \mathrm{cer}$ loci. Results are not yet available for two other recently defined (8) loci, namely cer-yk and $-y n$, which also have the phenotypic formula ++++
Despite the absence of genetic tests with five of the cer loci affecting barley spike waxes, the results presented demonstrate that the 17 dominant mutants under investigation belong to a cer locus which is not allelic with 36 of the previously defined spike loci. This new locus has been designated Cer-yy (8).

\subsection{Composition of waxes on spikes of four Cer-yy mutants compared with that on spikes and leaf blades of Bonus}

The low optical densities $(0.07,0.06,0.05$ and $0.05)$ of waxes from Cer-yy spikes $(966,968$, 975 and 984 , respectively) compared to that 


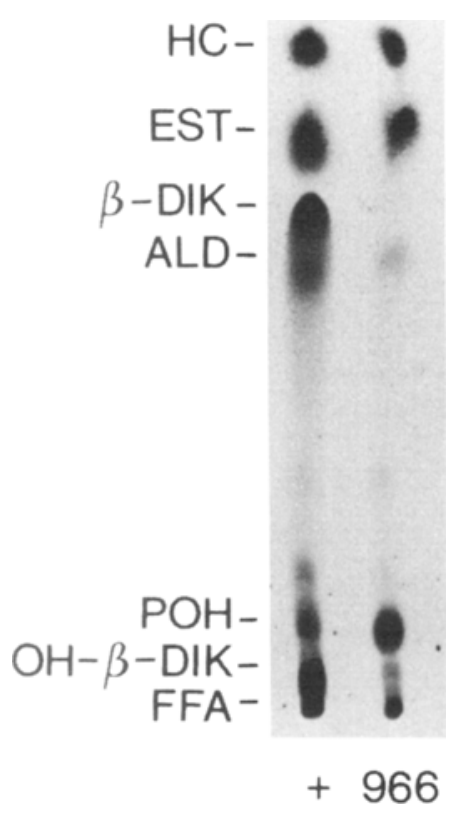

Figure 2. Composition of the epicuticular waxes on spikes of Bonus $(+)$ and $C e r-y y^{966}$ as revealed by TLC.

TLC patterns of the Cer-yy mutants 968,975 and 984 can not be distinguished from that shown for 966. The lipid classes were visualized by spraying with $55 \% \mathrm{H}_{2} \mathrm{SO}_{4}$ containing $0.6 \%(\mathrm{w} / \mathrm{v}) \mathrm{K}_{2} \mathrm{Cr}_{2} \mathrm{O}_{7}$, followed by charring.

(0.72; average of measurements from six different wax samples) of wild type spikes, suggested little if any $\beta$-diketones and/or hydroxy- $\beta$-diketones would be present in these mutant waxes (see 17). Figure 2 illustrates the difference in composition of the waxes found on wild type and Cer-yy spikes. All four investigated alleles at this locus determine waxes lacking $\beta$ - and hydroxy- $\beta$-diketones and having relatively increased proportions of primary alcohols, making the latter one of the three prominent lipid classes. The primary alcohols, however, do not dominate the wax as they do that from leaf blades and the lower leaf sheaths and internodes (see 14). The distribution of Cer-yy spike lipid classes is most similar to that from wild type awns (14).

The composition of the hydrocarbons (Table IV) present on Bonus spikes differs significantly from that on the leaf blades in that the $\mathrm{C}_{31}$ homologue predominates $(72 \%)$ on the former whereas the $\mathrm{C}_{33}$ homologue does so $(53 \%)$ on the latter. While the $\mathrm{C}_{31}$ homologue is also the major hydrocarbon in wax from the four Cer-yy mutants, the $\mathrm{C}_{33}$ homologue is more pronounced than in the wild type, amounting to $16 \%$ in the case of 966 . In the more than 30 thus far investigated cer spike mutants, the $\mathrm{C}_{33}$ homologue has always accounted for less than $4 \%$ of the hydrocarbons. Unlike the wax from leaves but similarly to that from spikes of wild type, the four mutants have relatively minor amounts of the 25 and 27 homologues.

An examination of the data in Table $\mathrm{V}$ reveals that the compositions of the free primary alcohols in the spike waxes of the four investigated mutants are indistinguishable from that characteristic for wild type leaf wax in which the $\mathrm{C}_{26}$ homologue predominates. This homologue accounts for only half the primary alcohols on Bonus spikes where the $C_{28}, 30$ and 32 chain lengths are also important components. Interestingly, in cer- $c^{36}$ and $-u^{69}$ spike waxes, a major portion of the $\mathrm{C}_{32}$ homologue is contributed by the awns $(21,22)$. This suggests that mutation of the Cer-yy locus influences synthesis of primary alcohols on the awns as well as on those cuticle surfaces of the spikes which in the wild type bear $\beta$-diketones. An increased prominence of the $C_{26}$ chain length is also evident in the aldehyde distributions (Table VI) of the three Cer-yy mutants 968,975 and 984 . This homologue is an important member of the aldehydes from wild type leaf but not spike wax. However, unlike leaf wax in which the 28 carbon chain is the other major homologue, the 32 carbon chain is conspicuous in the aldehydes of the wild type as well as in those of the three Cer-yy mutants mentioned above. The fourth mutant, 966, has the greatest amount $(61 \%)$ of the $\mathrm{C}_{32}$ homologue, and in addition $19 \%$ of the aldehydes are present as 34 carbon chains.

The distributions of chain lengths among the free acids from wild type leaves and spikes are quite similar, although somewhat less of the shorter 18 and 20 carbon chains and somewhat more of the longer 32 and 34 ones are found in waxes from the former vs the latter (Table VII). A greater difference is seen when comparing the free acid distributions from the four Cer-yy mutant waxes with those from the wild type 
Table IV

Composition of hydrocarbons present in the wax from spikes of four Cer-yy mutants plus spikes and leaves of wild type Bonus (weight $\%$ ).

\begin{tabular}{|c|c|c|c|c|c|c|}
\hline \multirow{2}{*}{$\begin{array}{l}\text { Number of } \\
\text { carbons }\end{array}$} & \multicolumn{5}{|c|}{ Spikes } & \multirow{2}{*}{$\begin{array}{c}\text { Leaves } \\
\text { Bonus }\end{array}$} \\
\hline & Bonus & 966 & 968 & 975 & 984 & \\
\hline 21 & 0.3 & 0.2 & 0.3 & 0.2 & 0.3 & \\
\hline 22 & 0.2 & 0.1 & $\operatorname{tr}$ & $\mathrm{tr}$ & $\mathrm{tr}$ & \\
\hline 23 & 1.5 & 2.7 & 2.9 & 1.1 & 2.3 & \\
\hline 24 & 0.2 & 0.3 & 0.2 & $\operatorname{tr}$ & 0.1 & \\
\hline $\mathrm{X}$ & & 0.3 & 0.3 & & & $\operatorname{tr}$ \\
\hline 25 & 2.0 & 2.9 & 3.3 & 2.1 & 4.1 & 8.5 \\
\hline 26 & 0.1 & 0.1 & 0.1 & 0.2 & 0.2 & 1.6 \\
\hline$X$ & 0.1 & 0.4 & 0.4 & 0.1 & $\mathrm{tr}$ & tr \\
\hline 27 & 2.0 & 2.8 & 3.2 & 1.8 & 3.3 & 6.8 \\
\hline 28 & 0.1 & 0.2 & 0.2 & 0.2 & 0.2 & 0.3 \\
\hline $\mathrm{X}$ & 0.1 & 0.4 & 0.6 & 0.2 & 0.1 & $\operatorname{tr}$ \\
\hline 29 & 14.7 & 7.5 & 12.9 & 10.2 & 13.5 & 8.6 \\
\hline 30 & $1.3 \mathrm{~b}$ & $1.1 \mathrm{~b}$ & $1.2^{b}$ & $0.9 \mathrm{~b}$ & $1.4 \mathrm{~b}$ & 0.2 \\
\hline $31 \mathrm{c}$ & 72.1 & 64.2 & 66.0 & 73.0 & 68.0 & 19.0 \\
\hline 32 & 1.0 & 1.1 & 0.9 & 0.9 & 0.6 & $\operatorname{tr}$ \\
\hline 33 & 4.1 & 15.8 & 7.5 & 9.1 & 5.8 & 52.8 \\
\hline 34 & & & & & & $\operatorname{tr}$ \\
\hline 35 & & & & & & 2.1 \\
\hline
\end{tabular}

a $\mathrm{X}$ represents a member of a second homologous series whose retention times are slightly less than the following normal hydrocarbon.

b Percent is overestimated as the $\mathrm{C}_{30}$ homologue has not been integrated separately from an unknown of approximately the same amount as $\mathrm{C}_{30}$.

c Includes the longest member of the $\mathrm{X}$ series which was too small to be resolved from the $\mathrm{C}_{31}$ hydrocarbon under the GLC conditions used.

$\operatorname{tr}=\operatorname{trace}(<0.1 \%)$.

Table V

Composition of free primary alcohols present in the wax from spikes of four Cer-yy mutants plus spikes and leaves of wild type Bonus (weight $\%$ as acetates).

\begin{tabular}{|c|c|c|c|c|c|c|}
\hline \multirow{2}{*}{$\begin{array}{l}\text { Number of } \\
\text { carbons }\end{array}$} & \multicolumn{5}{|c|}{ Spikes } & \multirow{2}{*}{$\begin{array}{l}\text { Leaves } \\
\text { Bonus }\end{array}$} \\
\hline & Bonus & 966 & 968 & 975 & 984 & \\
\hline 20 & & 0.9 & 1.5 & 0.4 & 0.6 & tr \\
\hline 22 & 1.5 & 0.3 & 0.5 & 0.4 & 0.3 & 1.0 \\
\hline 23 & $\operatorname{tr}$ & $\operatorname{tr}$ & $\operatorname{tr}$ & $\mathrm{tr}$ & $\operatorname{tr}$ & tr \\
\hline 24 & 6.5 & 2.9 & 2.7 & 2.4 & 2.7 & 4.1 \\
\hline 25 & 0.5 & 0.8 & 0.7 & 0.5 & 0.6 & 0.3 \\
\hline 26 & 50.8 & 85.8 & 85.9 & 83.7 & 86.6 & 89.7 \\
\hline 27 & 0.6 & 0.2 & 0.4 & 0.2 & 0.2 & 0.2 \\
\hline 28 & 16.4 & 4.3 & 5.9 & 5.9 & 6.7 & 3.8 \\
\hline 29 & 1.1 & $\mathrm{tr}$ & 0.1 & $\operatorname{tr}$ & tr & tr \\
\hline 30 & 12.0 & 0.5 & 1.2 & 1.4 & 1.0 & 0.5 \\
\hline 31 & 1.2 & 0.1 & 0.1 & 0.1 & $\mathrm{tr}$ & tr \\
\hline 32 & 9.1 & 3.2 & 1.1 & 4.3 & 1.3 & 0.2 \\
\hline 33 & & $\operatorname{tr}$ & & $\mathrm{tr}$ & & \\
\hline 34 & 0.2 & 1.2 & & 0.6 & & 0.2 \\
\hline
\end{tabular}

$\operatorname{tr}=\operatorname{trace}(<0.1 \%)$. 
Table VI

Composition of aldehydes present in the wax from spikes of four Cer-yy mutants plus spikes and leaves of wild type Bonus (weight $\%$ as alcohol acetates).

\begin{tabular}{|c|c|c|c|c|c|c|}
\hline \multirow{2}{*}{$\begin{array}{l}\text { Number of } \\
\text { carbons }\end{array}$} & \multicolumn{5}{|c|}{ Spikes } & \multirow{2}{*}{$\begin{array}{l}\text { Leaves } \\
\text { Bonus }\end{array}$} \\
\hline & Bonus & 966 & 968 & 975 & 984 & \\
\hline 20 & $\mathrm{tr}$ & $\mathrm{tr}$ & 0.2 & 0.5 & 2.0 & $\mathrm{tr}$ \\
\hline 22 & 0.1 & 0.1 & 0.7 & 1.1 & 3.5 & 0.3 \\
\hline 23 & & $\operatorname{tr}$ & $\mathrm{tr}$ & $\operatorname{tr}$ & tr & $\mathrm{tr}$ \\
\hline $24 a$ & 0.9 & 1.3 & 5.6 & 3.5 & 4.8 & 1.1 \\
\hline 25 & & 0.1 & 0.7 & 0.6 & 0.7 & 0.5 \\
\hline $26 \mathrm{a}$ & 4.1 & 10.2 & 22.0 & 29.9 & 32.8 & 39.7 \\
\hline 27 & 0.2 & 0.3 & 1.7 & 0.3 & 0.5 & 1.1 \\
\hline $28 \mathrm{a}$ & 8.4 & 3.9 & 9.1 & 7.5 & 10.8 & 45.9 \\
\hline 29 & 0.5 & tr & 0.5 & 0.4 & 0.3 & 0.7 \\
\hline $30 \mathrm{a}$ & 27.0 & 4.1 & 14.9 & 9.5 & 13.7 & 6.3 \\
\hline 31 & 1.9 & 0.4 & 0.9 & 1.1 & 1.0 & $\operatorname{tr}$ \\
\hline $32 \mathrm{a}$ & 54.8 & $60.8 \mathrm{~b}$ & 41.5 & 40.4 & 29.3 & 2.9 \\
\hline 33 & $\operatorname{tr}$ & & $\operatorname{tr}$ & $\operatorname{tr}$ & & tr \\
\hline 34 & 2.1 & 18.8 & 2.3 & 5.1 & 0.7 & 1.5 \\
\hline
\end{tabular}

a Includes minor amount of a member of a second homologous series whose retention times are slightly greater than those of the normal alcohol acetates.

b Includes minor amount of $\mathrm{C}_{33}$ which was not integrated separately.

$\operatorname{tr}=\operatorname{trace}(<0.1 \%)$.

Table VII

Composition of free acids present in the wax from spikes of four Cer-yy mutants plus spikes and leaves of wild type Bonus (weight $\%$ as methyl esters).

\begin{tabular}{|c|c|c|c|c|c|c|}
\hline \multirow{2}{*}{$\begin{array}{l}\text { Number of } \\
\text { carbons }\end{array}$} & \multicolumn{5}{|c|}{ Spikes } & \multirow{2}{*}{$\begin{array}{l}\text { Leaves } \\
\text { Bonus }\end{array}$} \\
\hline & Bonus & 966 & 968 & 975 & 984 & \\
\hline 16 & 4.8 & 3.8 & 1.8 & 3.2 & 3.7 & 2.0 \\
\hline 17 & $\mathrm{tr}$ & $\mathrm{tr}$ & $\operatorname{tr}$ & $\operatorname{tr}$ & tr & 0.2 \\
\hline 18 & $9.7 \mathrm{~b}$ & 2.8 & 1.9 & 2.5 & 2.3 & 2.7 \\
\hline 19 & $\operatorname{tr}$ & $\operatorname{tr}$ & $\operatorname{tr}$ & 0.1 & 0.4 & 0.1 \\
\hline 20 & 9.9 & 5.1 & 5.0 & 9.1 & 5.7 & 4.1 \\
\hline 21 & 0.3 & 0.4 & 0.4 & 0.5 & 0.4 & 0.3 \\
\hline 22 & 14.0 & 32.9 & 29.6 & 29.5 & 24.5 & 13.9 \\
\hline 23 & 0.5 & 0.9 & 0.9 & 0.7 & 0.8 & 0.2 \\
\hline 24 & 12.9 & 16.6 & 19.5 & 14.9 & 16.5 & 7.3 \\
\hline 25 & 0.3 & 0.4 & 0.6 & 0.3 & 0.4 & 1.5 \\
\hline 26 & 9.2 & 16.8 & 27.5 & 18.9 & 20.9 & 15.6 \\
\hline 27 & 0.2 & $\operatorname{tr}$ & 0.1 & tr & 0.7 & 2.2 \\
\hline 28 & 16.2 & 4.8 & 8.0 & 7.4 & 10.0 & 18.8 \\
\hline 29 & 0.7 & 0.1 & $\mathrm{tr}$ & 0.1 & 0.2 & 1.9 \\
\hline 30 & 12.0 & 2.5 & 2.7 & 4.0 & 6.7 & 15.3 \\
\hline 31 & 0.5 & 0.1 & $\operatorname{tr}$ & tr & tr & $\operatorname{tr}$ \\
\hline 32 & 6.1 & 8.2 & 1.8 & 7.4 & 6.0 & 9.0 \\
\hline 33 & $\operatorname{tr}$ & $\operatorname{tr}$ & & tr & $\operatorname{tr}$ & $\operatorname{tr}$ \\
\hline 34 & 0.3 & 2.7 & $\operatorname{tr}$ & 1.3 & 0.8 & 4.9 \\
\hline 36 & 0.1 & & & & & \\
\hline Unknownsc & 2.1 & 1.8 & 0.1 & $\operatorname{tr}$ & $\operatorname{tr}$ & $\operatorname{tr}$ \\
\hline
\end{tabular}

a The trace to very small amounts of $\mathrm{C}_{14}$ often observed are not included since their volatility leads to preferential losses during isolation and preparation of the methyl esters.

b Probably overestimated because of contamination of wax sample by internal lipids

c Primarily two components which elute shortly before normal $\mathrm{C}_{18}$ and $\mathrm{C}_{20}$ acid methyl esters.

$\operatorname{tr}=\operatorname{trace}(<0.1 \%)$. 
Composition of the ester acids present in the wax from spikes of four $\mathrm{Cer}-y y$ mutants plus spikes and leaves of wild type Bonus (weight $\%$ as methyl esters).

\begin{tabular}{|c|c|c|c|c|c|c|}
\hline \multirow{2}{*}{$\begin{array}{l}\text { Number of } \\
\text { carbons }\end{array}$} & \multicolumn{5}{|c|}{ Spikes } & \multirow{2}{*}{$\begin{array}{l}\text { Leaves } \\
\text { Bonus }\end{array}$} \\
\hline & Bonus & 966 & 968 & 975 & 984 & \\
\hline 16 & 11.0 & 5.9 & 6.0 & 6.1 & 11.4 & 3.2 \\
\hline 17 & & $\operatorname{tr}$ & $\operatorname{tr}$ & $\mathrm{tr}$ & $\mathrm{tr}$ & tr \\
\hline 18 & 12.3 & 7.3 & 7.7 & 9.8 & 11.5 & 11.8 \\
\hline 19 & 0.1 & $\mathrm{tr}$ & 0.2 & $\operatorname{tr}$ & 0.2 & tr \\
\hline 20 & 57.1 & 36.2 & 41.7 & 54.2 & 42.0 & 34.4 \\
\hline 21 & $\operatorname{tr}$ & 0.6 & 0.8 & 0.6 & 0.5 & 0.2 \\
\hline 22 & 16.5 & 31.1 & 27.4 & 22.7 & 23.0 & 35.4 \\
\hline 23 & $\operatorname{tr}$ & 0.2 & 0.2 & $\operatorname{tr}$ & $\operatorname{tr}$ & tr \\
\hline 24 & 2.9 & 12.9 & 11.6 & 5.5 & 7.6 & 5.7 \\
\hline 25 & $\operatorname{tr}$ & 0.2 & 0.4 & $\operatorname{tr}$ & $\operatorname{tr}$ & tr \\
\hline 26 & 0.1 & 5.5 & 4.0 & 1.0 & 3.5 & 9.0 \\
\hline 27 & & $\operatorname{tr}$ & $\operatorname{tr}$ & & & tI \\
\hline 28 & & $\operatorname{tr}$ & $\operatorname{tr}$ & & 0.2 & 0.2 \\
\hline 30 & & & & & & $\operatorname{tr}$ \\
\hline Unknownsa & & & $\operatorname{tr}$ & $\operatorname{tr}$ & & tr \\
\hline
\end{tabular}

a Consists of two components which have slightly shorter retention times than normal $\mathrm{C}_{18}$ and $\mathrm{C}_{20}$ acid methyl esters.

$\operatorname{tr}=\operatorname{trace}(<0.1 \%)$.

\section{Table IX}

Composition of the ester alcohols present in the wax from spikes of four Cer-yy mutants plus spikes and leaves of wild type Bonus (weight $\%$ as acetates).

\begin{tabular}{|c|c|c|c|c|c|c|}
\hline \multirow{2}{*}{$\begin{array}{l}\text { Number of } \\
\text { carbons }\end{array}$} & \multicolumn{5}{|c|}{ Spikes Leaves } & \multirow{2}{*}{ Leaves } \\
\hline & Bonus & 966 & 968 & 975 & 984 & \\
\hline $\begin{array}{l}\text { Alkan-2-olsa } \\
\text { Alkan-1-ols }\end{array}$ & 12.4 & & & & & \\
\hline 16 & & 0.8 & 1.2 & $\operatorname{tr}$ & $\operatorname{tr}$ & \\
\hline 17 & & $\operatorname{tr}$ & 0.1 & & & \\
\hline 18 & 0.3 & 2.4 & 4.7 & 1.8 & 4.6 & 2.0 \\
\hline 19 & $\operatorname{tr}$ & 0.1 & 0.1 & $\operatorname{tr}$ & $\operatorname{tr}$ & $\operatorname{tr}$ \\
\hline 20 & 1.8 & 6.6 & 6.2 & 4.8 & 7.1 & 0.7 \\
\hline $21^{b}$ & $\operatorname{tr}$ & $\operatorname{tr}$ & $\operatorname{tr}$ & $\operatorname{tr}$ & $\operatorname{tr}$ & $\operatorname{tr}$ \\
\hline 22 & 19.0 & 13.4 & 16.4 & 13.3 & 18.2 & 4.7 \\
\hline 23 & 0.4 & 0.4 & 1.6 & 0.1 & 0.4 & $\mathrm{tr}$ \\
\hline 24 & 20.7 & 13.0 & 15.3 & 11.4 & 15.7 & 4.5 \\
\hline 25 & 0.5 & 1.6 & 1.9 & 0.6 & 0.8 & 0.1 \\
\hline 26 & 32.3 & 58.4 & 48.4 & 62.3 & 49.9 & 82.3 \\
\hline 27 & 0.2 & 0.2 & 0.2 & 0.2 & 0.3 & 0.1 \\
\hline 28 & 5.8 & 2.6 & 3.2 & 4.3 & 2.8 & 5.1 \\
\hline 29 & 0.2 & tr & $\operatorname{tr}$ & $\operatorname{tr}$ & $\operatorname{tr}$ & $\operatorname{tr}$ \\
\hline 30 & 2.1 & 0.2 & 0.5 & 0.5 & 0.1 & 0.4 \\
\hline 31 & 0.3 & $\operatorname{tr}$ & & $\operatorname{tr}$ & $\mathrm{tr}$ & \\
\hline 32 & 4.1 & 0.3 & $\operatorname{tr}$ & 0.7 & 0.2 & \\
\hline
\end{tabular}

a Includes $C_{13}, C_{15}$ and $C_{17}$. Underestimated as the volatility of the $C_{13}$ homologue leads to preferential losses during preparation of the alcohol acetates (20). May also include some 16 carbon alkan-1-ol (see Table X, footnote a).

b Presence of $\mathrm{C}_{21}$ is assumed since both $\mathrm{C}_{19}$ and $\mathrm{C}_{23}$ are found. The amount is not measurable as contamination by a phthalate having the same retention time occurs during sample preparation (22).

$\operatorname{tr}=\operatorname{trace}(<0.1 \%)$. 
Table X

Composition of esters present in the wax from spikes of four Cer-yy mutants plus spikes and leaves of wild type Bonus (weight $\%$ ).

\begin{tabular}{|c|c|c|c|c|c|c|}
\hline \multirow{2}{*}{$\begin{array}{c}\text { Number of } \\
\text { carbons }\end{array}$} & \multicolumn{5}{|c|}{ Spikes } & \multirow{2}{*}{$\begin{array}{l}\text { Leaves } \\
\text { Bonus }\end{array}$} \\
\hline & Bonus & 966 & 968 & 975 & 984 & \\
\hline \multicolumn{7}{|l|}{$\begin{array}{l}\text { Alkan-2-ol } \\
\text { esters }\end{array}$} \\
\hline 29 & $\operatorname{tr}$ & & & & & \\
\hline 31 & 0.7 & & & & & \\
\hline 33 & 11.2 & & & & & \\
\hline 35 & 16.9 & & & & & \\
\hline $37 \mathrm{a}$ & 3.2 & & & & & \\
\hline Unknownsb & $\mathrm{tr}$ & & & & & \\
\hline \multicolumn{7}{|l|}{$\begin{array}{l}\text { Alkan-1-ol } \\
\text { esters }\end{array}$} \\
\hline 36 & & & 0.1 & $\operatorname{tr}$ & 0.3 & \\
\hline 37 & & & $\operatorname{tr}$ & tr & $\operatorname{tr}$ & \\
\hline 38 & 2.1 & 1.1 & 3.5 & 2.3 & 3.8 & $\operatorname{tr}$ \\
\hline 39 & $\mathrm{~m}$ & $\operatorname{tr}$ & $\operatorname{tr}$ & $\operatorname{tr}$ & 0.1 & \\
\hline 40 & 5.7 & 6.4 & 6.9 & 4.7 & 7.4 & 0.2 \\
\hline 41 & $\mathbf{m}$ & 0.3 & 0.5 & 0.4 & 0.5 & $\operatorname{tr}$ \\
\hline 42 & 12.6 & 19.9 & 17.1 & 14.2 & 18.7 & 4.6 \\
\hline 43 & m & 0.3 & 0.3 & 0.3 & 0.5 & tr \\
\hline 44 & 14.9 & 18.3 & 18.1 & 17.5 & 17.8 & 12.3 \\
\hline 45 & $\mathrm{~m}$ & 0.5 & 0.5 & 0.7 & 0.7 & tr \\
\hline 46 & 17.4 & 26.5 & 25.5 & 37.1 & 26.3 & 31.7 \\
\hline 47 & $\mathrm{~m}$ & 0.8 & 0.6 & 1.0 & 1.1 & tr \\
\hline 48 & 7.4 & 16.2 & 15.4 & 15.7 & 14.2 & 32.8 \\
\hline 49 & $\mathrm{~m}$ & 0.3 & $\mathrm{~m}$ & $\mathrm{~m}$ & 0.5 & tr \\
\hline 50 & 4.9 & 7.2 & 8.5 & 4.8 & 6.6 & 6.6 \\
\hline 51 & $\mathrm{~m}$ & $\mathrm{~m}$ & $\mathrm{~m}$ & $\operatorname{tr}$ & $\mathrm{m}$ & tr \\
\hline 52 & 3.0 & 2.0 & 2.9 & 1.2 & 1.6 & 8.1 \\
\hline 53 & & & & & & $\operatorname{tr}$ \\
\hline 54 & & & 0.1 & & & 2.8 \\
\hline 56 & & & & & & 0.8 \\
\hline
\end{tabular}

a Probably contains a small amount of 36 carbon alkan-1-ol esters (see 20). On the GLC columns used, 37 carbon alkan-2-ol and 36 carbon alkan-1-ol esters appear as a single peak.

b Semi-log plots of apparent carbon number vs retention time from isothermal GLC on $3 \%$ SP-2100 columns v suggest that they are $\mathrm{C}_{30}, \mathrm{C}_{32}, \mathrm{C}_{34}$ and $\mathrm{C}_{36}$ alkan-2-ol containing esters.

$\operatorname{tr}=\operatorname{trace}(<0.1 \%)$.

$\mathrm{m}=$ minor odd chain length alkan-1-ol containing ester integrated together with preceeding even chain homologue from which they were not completely separated by the $1 \%$ Dexsil-300 columns used. Visually they are of the same size or smaller than the shorter odd chain length homologues which were better separated by the columns.

waxes. In the mutant fatty acids the $\mathrm{C}_{22}$ homologue is quite important. Furthermore, whereas the sum of the 22, 24 and 26 homologues in the four mutants accounts for 62 to $77 \%$ of this wax class, it amounts to only $37 \%$ of the wild type's free acids. The $\mathrm{C}_{28}$ and longer homologues are less important members of the mutant free acids than they are of those of the wild type.

The data in Table VIII indicate that the compositions of the ester acids from the mutants 966, 968 and 984 are not like that of the wild 
type spike wax, but tend to be more similar to that of the wild type leaf wax. Specifically, the importance of the $\mathrm{C}_{20}$ homologue is decreased to the benefit of the $\mathrm{C}_{22}, 24$ and 26 homologues. When the compositions of the ester alcohols are examined (Table IX), a decided shift towards that typical for leaf wax is apparent for all four mutants. As characteristic for leaf wax esters, no alkan-2-ols are found. While the $\mathrm{C}_{26}$ homologue accounts for at least half of the ester alcohol moieties, it is not so dominating as in the wild type leaf wax esters ( $83 \%$ ), but certainly more important than in the wax esters from the wild type spikes (32\%). The total ester compositions are compared in Table $\mathrm{X}$. The distributions confirm the conclusion drawn from the ester alcohol data, namely, that the mutant and wild type leaf blade esters contain only alkan-l-ols. If the chain length distribution of the alkan-l-ol containing esters from Bonus spikes is calculated $\left(C_{38}=3.1, C_{40}=8.4, C_{42}=18.5, C_{44}=\right.$ $21.9, \mathrm{C}_{46}=25.6, \mathrm{C}_{48}=10.9, \mathrm{C}_{50}=7.2$ and $\left.\mathrm{C}_{52}=4.4\right)$ and then compared with the ester distributions from the mutants, no striking differences are apparent. Although a small increase in the 46 carbon chain ester of the four mutants has occurred, this chain length is nowhere near so prominent as in the wild type leaf blade ester spectrum. In this connection it is interesting that mutant 975 which showed the greatest modification of its ester alcohol moieties (Table IX) had ester acids (Table VIII) almost identical to those of the wild type.

\section{DISCUSSION}

The complex of enzymes known as fatty acid synthetase (fas) carries out de novo synthesis of fatty acids. That is, to an activated primer a number of short carbon chains donated by an activated elongating agent are successively added until a given chain length, most frequently $C_{16}$, is attained. For each addition and preparation of the growing chain for the next, as many as seven different enzymatic reactions can be involved. The enzyme system(s) carrying out further elongation of fatty acyl chains to those lengths $\left(\geqslant \mathrm{C}_{20}\right)$ characteristic of the epicuticular wax lipids is known as an elongase. Since the addition of each $\mathrm{C}_{2}$-unit from the donor malonyl-CoA presumably requires a similar series of reactions to those occurring in de novo synthesis, an elongase must be an enzyme complex very similar to fas. Presently available evidence suggests that de novo fas synthesis in plant epidermal cells gives rise to the substrates for the wax elongase which is located in the plasmalemma and/or cell walls of the same cells (see 11). Differential modification of the biosynthesis of the wax carbon chains by inhibitors, genetic mutation and photoperiodic treatments are best interpreted by the existence of several elongases (see 18, 2, 19). Before arriving on the cuticle surface, the resulting pools of fatty acyl chains can either serve as substrates for associated pathways such as decarboxylation or reduction, or simply be relased from the elongase(s) as free acids (see 18).

The most clearly differentiated elongases are those in barley giving rise to the alkanes and $\beta$ diketones (see 18, 10). The former system, known as an acyl elongase (12), presumably uses $\mathrm{C}_{16}$ and/or $\mathrm{C}_{18}$ fatty acyl chains as substrates to yield the spectrum of carbon chains composing the alkanes. The latter system, known as a $\beta$ ketoacyl elongase (12), utilizes only $C_{16}$ or shorter fatty acyl chains to construct the carbon skeleton of the $\beta$-diketones (96\% hentriacon$\tan -14,16$-dione; 10). In the following discussion no attempt will be made to differentiate between the various sequential and/or parallel elongation systems that might be involved in the synthesis of the non $\beta$-ketoacyl elongase derived lipids (18). Exactly how these two elongase systems differ is not known. Two possibilities can be envisaged: either the $\beta$-ketoacyl elongase system is involved in modifying the fas product(s) to $\beta$-ketoacyl chains which are then elongated by the acyl elongase and/or the $\beta$ ketoacyl elongase requires $\beta$-ketoacyl chains as the initial substrate for elongation. While an acyl elongase must function in all barley epidermal cells, e.g., those of the leaf blades, the $\beta$-ketoacyl elongase is restricted to given epidermal cells such as those of the spike lemmas, paleas and glumes (14) where it and the acyl elongase both function in the same cell.

Synthesis of the $\beta$-diketone lipids is either eliminated or reduced by mutations at all investigated cer spike loci. A reduction in amount is not accompanied by an alteration in structure or chain length composition (vON 
WETTSTEIN-KNOWLES, unpubl.). Reduction is eXpected as the mutants are selected on the basis of a change of color from blue-grey to yellowgreen that is correlated with the amount of $\beta$ diketones present in the wax (see 18). Some of the spike cer loci have no effect on the other wax lipids, e.g., the cer-cqu region (22). Such genes must influence reactions unique to the $\beta$-ketoacyl elongase system. Mutations at many cer spike loci, however, also alter the composition of one or more of the non $\beta$-ketoacyl elongase derived wax lipid classes. This behavior suggests that the acyl and $\beta$-ketoacyl elongase systems have structural or regulatory components in common (18). The mutations in the Cer-yy gene fall into the latter category as the data in this paper demonstrate. The Cer-yy locus can be distinguished from all the other cer loci in the same category because the chain length distributions of the non $\beta$-ketoacyl elongase derived lipids are modified markedly towards those characteristic for leaf blade waxes. A second unique attribute of the Cer-yy gene is that all 17 identified mutant alleles are dominant, indicating that the gene product is a regulatory component which can affect the expression of genes on both homologous chromosomes. Only one other dominant mutation has been identified out of the 1338 mutations assigned to the various cer loci (8).

The pertinent question to be asked at this point, is how to interpret the Cer-yy gene in light of our present understanding of the synthesis of the epicuticular wax lipids. We should like to suggest that the Cer-yy gene determines a regulatory component that upon mutation activates in the spike the genes for the leaf blade acyl elongase system and at the same time represses both the spike acyl and $\beta$-ketoacyl elongase systems which in the mutants are functional in the epidermal cells of the uppermost leaf sheaths. The testing of this hypothesis awaits the isolation and characterization of the fas and various elongase systems from barley epidermal cells, a project that has been initiated.

\section{ACKNOWLEDGEMENTS}

We are indebted to M. PETERSEN for outstanding technical assistance; to $\AA$. GUST AFssON and L. EHRENBERG for carrying out the chemical mutagen treatments and the chronic irradiations with ${ }^{137}$ Cs at Bogesund, Sweden; to A. S. STEINHOLZ and N. RASMUSSEN for preparing the figures; to the personnel of the Phytotron in Stockholm for growing the plants; and to the Nilsson-Ehle Fund and the Swedish Agricultural Research Council (grants 5076/B 3656 and 5270/B 3786) for financial support. U.L. also thanks A. LUNDQvisT for stimulating discussions.

\section{REFERENCES}

1. Ahnström, G. \& L. Ehrenberg: Dosimetry of mixed neutron-gamma radiations in the Stockholm reactor, R-1. In: Selected topics in radiation dosimetry. Proc. Symp. IAEA, Vienna p. 603 (1961)

2. Avato, P., J. D. Mikkelsen \& P. von WettSTEIN-KNOWLES: Effect of inhibitors on synthesis of fatty acyl chains present in waxes on developing maize leaves. Carlsberg Res. Commun. 45, 329-347 (1980)

3. Dormling, I., A. Gustafsson, H. R. Jung \& D. voN WETtSTEIN: Phytotron cultivation of Svalöfs Bonus barley and its mutant Svalörs Mari. Hereditas (Lund) 56, 221-237 (1966)

4. Dormuing, I., $\AA$. Gustafsson \& D. von WettSTEIN: Phytotron cultivation of Bonus barley: The control of maturation and grain quality. Hereditas (Lund) 63, 415-428 (1969)

5. Gustarsson, A. \& U. LundQvist: Controlled environment and short-day tolerance in barley mutants. In: Induced mutations in cross-breeding. Proc. Symp. IAEA, Vienna. pp. 45-53 (1976)

6. Gustafsson, $\AA . \&$ U. Lundevist: Mutations and parallel variation. In: Induced mutations - a tool in plant breeding. Proc. Symp. IAEA. Vienna. pp. 85-110 (1981)

7. Lundovist, U. \& D. von Wettstein: Induction of eceriferum mutants in barley by ionizing radiations and chemical mutagens. Hereditas (Lund) 48, 342-362 (1962)

8. Lundevist, U. \& D. von Wettstein: Stock list for the eceriferum mutants. VI. Barley Genetics Newsletter 12, (in press) (1982)

9. Lundovist, U., P. von WetTSTEIN-KnOWles \& D. VON WETTSTEIN: Induction of eceriferum mutants in barley by ionizing radiations and chemical mutagens II. Hereditas (Lund) 59, 473504 (1968)

10. Mikkelsen, J. D.: Structure and biosynthesis of $\beta$-diketones in barley spike epicuticular wax. Carlsberg Res. Commun. 44, 133-147 (1979) 
11. Mikkelsen, J. D.: Synthesis of lipids by epidermal and mesophyll protoplasts isolated from barley leaf sheaths. In: Biogenesis and function of plant lipids. P. Mazliak, P. Benveniste, C. Costes \& R. Douce eds., Elsevier/North Holland Biomedical Press. Amsterdam. pp. 285-290 (1980)

12. Mikkelsen, J. D. \& P. von Wettstein-KnowLES: Biosynthesis of esterified alkan-2-ols. 23rd Intl. Conference on the Biochemistry of Lipids, Nyborg, Denmark, p. 99 (1981)

13. Nyвом, N.: Mutation types in barley. Acta Agric. Scand. 4, 430-456 (1954)

14. Simpson, D. \& P. von Wettstein-Knowles: Structure of epicuticular waxes on spikes and leaf sheaths of barley as revealed by a direct platinum replica technique. Carlsberg Res. Commun. 45, 465-481 (1980)

15. Wettstein, D. von: The phytotron in Stockholm. Studia Forest. Suecica 44, 1-23 (1967)

16. Wettstein-Knowles, P. von: The molecular phenotypes of the eceriferum mutants. In: Proc. 2nd Int. Barley Genet. Symp. (1969) R. A. Nilan ed., Pullman, Wash., USA, Washington State Univ. Press, pp. 146-193 (1971)

17. Wettstein-Knowles, $P$. von: Genetic control of $\beta$-diketone and hydroxy- $\beta$-diketone synthesis in epicuticular waxes of barley. Planta (Berl.) 106, 113-130 (1972)

18. Wettstein-Knowles, P. von: Genetics and biosynthesis of plant epicuticular waxes. In: Advances in the biochemistry and physiology of plant lipids. L. A. Appelqvist \& C. Liljenberg eds., Elsevier/North Holland Biomedical Press. Amsterdam, pp. 1-26 (1979)

19. Wettstein-Knowles, P. von, P. Avato \& J. D. MIKKELSEN: Light promotes synthesis of the very long fatty acyl chains in maize wax. In; Biogenesis and function of plant lipids. P. Mazliak, P. Benveniste. C. Costes \& R. Douce eds., Elsevier/North Holland Biomedical Press, Amsterdam, pp. 271-274 (1980)

20. Wettstein-Knowles, P. von \& A. G. Netting: Esterified alkan-l-ols and alkan-2-ols in barley epicuticular wax. Lipids 11, 478-484 (1976)

21. Wettstein-Knowles, P. von \& A. G. Netting: Composition of epicuticular waxes on barley spikes. Carlsberg Res. Commun. 41, 225-235 (1976)

22. Wettstein-Knowles, P. von \& B. Søgaard: The cer-cqu region in barley: Gene cluster or multifunctional gene. Carisberg Res. Commun. $45,125-141(1980)$ 